\title{
THE RF CENTRAL BANK'S COURSE IS TO ACHIEVE MEDIUM-RUN STABILITY ${ }^{1}$
}

\author{
Ye. Goryunov, P. Trunin
}

The Bank of Russia medium-run monetary policy course is to remain unchanged: the regulator will continue its efforts to bring the inflation rate down to $4 \%$ in 2017. This follows from the draft of the Guidelines for the Single State Monetary policy in 2016 and for 2017 and 2018. For this goal to become achievable under the existing conditions, the monetary authorities will have to maintain the key rate at its present-day level. The reasons for this state of affairs are the high inflation expectations and a slower decline in its rate than has been expected.

The medium-run strategic vector of monetary policy in Russia will remain unchanged. This follows from the draft of the Guidelines for the Single State Monetary policy in 2016 and for 2017 and 2018, adopted as of 14 October 2015. The Bank of Russia intends to pursue its inflation targeting policy in the framework of a freely floating exchange rate regime through managing the key rate, which determines the average rates on the interbank lending market. The medium-run inflation target is set at $4 \%$, and the regulator predicts that the growth rate of consumer prices can be reduced to that level as early as 2017. The decisions concerning the key rate's level, as before, will be designed to properly balance the inflation risks and the risks of more considerable economy cooling. At the same time, financial sustainability remains one of the regulator's priorities. Among the important factors that underlie the Russian financial system's resilience we may point to the international reserves held by the Bank of Russia, and it intends to further increase the amount of these assets.

The macroeconomic situation continues to be strongly dependent on the external factors, and according to the RF Central Bank, the most important among them are the monetary policies pursued by the USA and other major developed countries, and the situations in China's economy and in the hydrocarbon market. With due regard for all these circumstances, the RF Central Bank put forth several economic development scenarios for the next three years, which differ primarily in their oil price movement projections.

According to the baseline scenario, the price for oil will remain at its current level (about $\$ 50$ per barrel) over the next three years, and so in 2016, under these conditions, recession in Russia's economy will persist, while economic growth recovery will begin only in 2017. The optimistic scenario envisages a gradual rise of the price of oil towards $\$ 75$ per barrel in 2018. The GDP growth rate in 2016 will remain at zero level, and in 2017 it will rise to approximately $2 \%$. The stress scenario is geared to a slump in the oil price below $\$ 40$ per barrel, followed by a new decline of the ruble's exchange rate against the world's major currencies, rising prices and a deeper and longer

1 This paper was originally published in Online Monitoring of Russia's Economic Outlook No.16. 
economic decline. None of these scenarios expects that the economic sanctions may be lifted. On the whole, the suggested three scenarios map the most probable variants of the future course of events. It should be noted that the stress scenario is not presented in detail, which we believe to be unjustified because its realization in actual practice appears to be quite probable.

In our opinion, the strategy selected by the Bank of Russia is sufficiently correct. Inflation targeting under a freely floating exchange rate regime is a rather widespread monetary policy regime, implemented not only by many developed countries, but also by the transition economies. The regime under which the currency rates are determined by market force is an important tool whereby the effects of external shocks can be mitigated, to ensure stability in the balance of payments and economic activities. Thus, the RF Central Bank's decision to continue its policy of non-interference in the foreign exchange market also appears to be sound.

It should be noted that inflation targeting represents a flexible monetary policy regime, whereby it becomes possible to promptly respond to current changes in the economic situation. This means that, whenever necessary, the RF Central Bank will be able to alter the course of its policy in response to any new challenges and shocks.

The RF Central Bank reserves the right to carry out interventions in the foreign exchange market whenever there may arise a threat to its financial sustainability. It is critically important to maintain a stable financial system, especially in the Russian economy with its highly volatile capital flows and foreign trade condition.

In its draft document, the Bank of Russia emphasizes that its official mandate by no means implies the obligation to maintain a fixed foreign exchange rate regime. In accordance with the RF Constitution (Article 75, Part 2), the RF Central Bank is indeed obliged to ensure the national currency's exchange rate stability, but it would be wrong to interpret this provision as the duty to fix the ruble's exchange rate against one or other foreign currency. To ensure the ruble's stability means to protect its purchasing power, a goal that can be achieved through reducing inflation and increasing the predictability of its movement. This is indeed the main goal of the inflation targeting regime, as stipulated in the draft document prepared by the Bank of Russia. Therefore its refusal to manage directly the foreign exchange rate and the resulting free movement of currency rates in the foreign exchange market cannot be regarded as contrary to the official mandate held by the RF Central Bank. In fact, our interpretation of the mandate granted to the monetary authorities is exactly the same as that offered in the draft.

At the same time, inflation targeting does not imply that the actual situation in the foreign exchange market should be completely ignored, because the movement of the exchange rate is the most important factor that influences the inflation index. Insofar as the interest rate policy can determine the exchange rate, it may be employed to suppress the inflation processes caused by depreciatory pressures. We consider this practice to be correct, and according to its draft document, the Bank of Russia is going to follow this course.

Meanwhile, in our opinion, the RF Central Bank's intention to replenish its international reserves has given rise to some questions. Of course, these reserves are to a certain degree a guarantee of macroeconomic stability, and they boost the confidence of economic agents in the ability of the monetary 
authorities to properly handle the tricky financial situation. Nevertheless, the experience of replenishing Russia's international reserves in 2015 can hardly be called successful, as this was done in the wake of huge donations of foreign currency to the banking system in the form of refinancing. In other words, at first the RF Central Bank applied an upward pressure to the ruble's exchange rate by granting foreign exchange liquidity to banks, and afterwards began to purchase foreign currency. Under the expectably difficult macroeconomic conditions over the next few years, replenishment of international reserves may upset the existing balance in the foreign exchange market, thus causing a new inflation surge. Thus, we believe that the renewal of currency purchases in the foreign exchange market can be possible only if foreign trade and capital flows demonstrate some significant improvement.

According to the baseline scenario projections prepared by the RF Central Bank, which rely on the assumption that the future developments in the Russian economy will be determined by inertia, in 2016 the inflation index will hover around 5.5-6.5\%, and by 2017 it will get down to its target of $4 \%$. The factors responsible for this decline of the price growth index will be weak output growth and the stabilization of oil prices at their current level. In our opinion, even with due regard for these factors with their suppressive influence on the price growth index, it can hardly be possible to reduce inflation to this target level without an excessively painful monetary policy toughening.

The ongoing inflation processes in Russia are sufficiently inertial, and so we believe that, in the framework of the baseline (inertia-oriented) scenario, it would be more reasonable to expect the inflation index to move at the rate of $6-8 \%$ in 2016 , and $5-7 \%$ in 2017 . It is noteworthy that, as stated by the Bank of Russia itself, the expectations of economic agents with regard to next year's price growth are still high, at the level of approximately $15 \%$.

Over several previous years, the Bank of Russia systematically underestimated its inflation targets, and so the actual growth rate displayed by the Consumer Price Index (CPI) was above its target value. At the same time, the regulator chose to abstain from a rigid targeting policy in respect of the Consumer Price Index's growth rate. Whenever the inflation rose above the target level, the Bank of Russia never attempted any radical toughening of its monetary policy, thus undermining the confidence of economic agents in their future prospects. Meanwhile, the trust of economic agents in the policy pursued by the central bank is the key factor that determined the success of the inflation targeting regime. Therefore we believe that the Bank of Russia should have been oriented, in its forecasts, to a somewhat higher inflation level, while keeping its long-term target at $4 \%$.

It should be noted that in our opinion, in addition to the absence, in the draft, of any detailed information the stress scenario of economic development, the draft also lacks the RF Central Bank's comments on some important aspects of its policy. An economic slump is usually associated with growth of dubious debts owed to banks. Under these conditions, we should like to see in the draft some estimates of the banking sector's sustainability and the probability of the onset of a bad-debt crisis in face of moderately high interest rates.

The continuing practice of revocation of banking licenses has increased the pressure on the Deposit Insurance Agency. The toughened US monetary policy and the economic growth slowdown in China are expected to cause a surge in capital outflow from the newly emerging markets, probably to be 
followed by a fall of prices for energy carriers. In such circumstances, it is inevitable that the amount of stake debt will be on the rise, and the banking sector may be faced with the risk of destabilization, thus forcing the RF Central Bank to alter its currently implemented monetary policy course. The Bank of Russia is obviously well aware of this threat, but it has chosen not to offer any estimates or information as to how it intends to overcome these trends. It is still unclear if the regulator considers the set of instruments that has been applied for this purpose over the past one-and-a-half years to be sufficient to prevent the development of such a crisis.

The Russian economy is now faced with the risk of stagflation, which has been caused by both the domestic structural problems and the external shocks. In such a situation it is especially important to focus on bringing down the prevailing inflation expectations and to properly balance the efforts to boost economic activity and the measures designed to suppress price growth. The leading role in preventing the threat of a multi-year stagflation period belongs to the monetary authorities. The current policy pursued by the Bank of Russia can significantly reduce the risk of such a course of events. Thus, in particular, the decision, adopted as of 30 October, that the RF Central Bank's key rate and the interest rates on liquidity provision and absorption open market operations should be kept unchanged is perfectly in line with this policy.

It should be reminded that over the course of this year, the RF Central Bank has been consistently reducing the key rate after its abrupt raise in December 2014 in order to stabilize the situation in the financial market. For the last time, the key rate was reduced at the Bank of Russia Board of Directors' meeting on 3 August. However, at its last but one meeting on 11 September, the regulator chose to leave it unchanged. The main reason behind this policy of the RF Central Bank is that both the actual inflation index and the inflation expectation remain high, in spite of the relative stabilization in the real sector of the economy.

According to the month-end result for October 2015, the inflation index in per annum terms (for the previous 12-month period) amounted to $15.6 \%$, which means that, since last summer, practically no inflation slowdown on the previous year could be observed. Over January-October, prices rose by $11.2 \%$, and over the period 1 November through 9 November - by another $0.3 \%$. This means that the CPI for November may amount to approximately $1 \%$, and its year-end value - to more than $13 \%$.

Of course, towards the end of the year 2015 the inflation index in per annum terms will inevitably decline, because the inflation surge in late 2014 was caused by the ruble's significant downfall - something that is unlikely to occur once again. But the rate of inflation decline has turned out to be lower than expected.

In such a situation the RF Central Bank's decision that the key rate should be maintained at the same level appears to be quite justified. Neither the loosening of the RF CB's monetary policy nor the softening of its lending standards appear to be feasible while the real interest rates on loans issued to non-financial organizations are remaining low, and the inflation risks is remaining persistently high. Besides, the reduced rate could translate into a new wave of the ruble's weakening and an increased inflationary pressure. 